\title{
К вопросу о модальностях сопряжения и разграничения канонического права и права государственного
}

\author{
Исидор, митрополит Смоленский и Дорогобужский (Тупикин Р.В.) \\ Смоленская Православная Духовная Семинария Смоленской Епархии \\ Русской Православной Церкви \\ Россия, 214000, г. Смоленск, ул. Тимирязева, д. 5 \\ E-mail: tupikinrv2017@mail.ru
}

\begin{abstract}
Аннотация. Автор исследует и объясняет природу, особенности и способы влияния церковного канонического права на право государственное, а также показывает причины научного интереса к этим вопросам. По мнению автора, влияние канонического права (Lex Canonica) на право государственное прежде всего проявляется в признании государственными судебными органами норм канонического права и решений религиозных судов религиозных организаций. Поэтому в статье исследована обширная современная судебная практика (США и Канады), показывающая признание судами (государством) автономной исключительной компетенции за религиозными организациями в истолковании норм канонического права. Сделан вывод о различности права государственного и права церковного (Lex Canonica) по природе, источниковой основе, структуре и онтологии, но, вместе с тем, по мнению автора, эти две нормативные системы сложным образом взаимодействуют, взаимно влияют друг на друга.
\end{abstract}

Ключевые слова: церковное право, каноническое право, теология, государственное право, пересечения в праве.

Для цитирования: Исидор (Тупикин Р.В.), митрополит Смоленский и Дорогобужский. 2020. К вопросу о модальностях сопряжения и разграничения канонического права и права государственного. NOMOTHETIKA: Философия. Социология. Право. 45 (4): 781-791. DOI 10.18413/2712-746X-2020-45-4-781-791

\section{On the question of the modalities of joining and differentiating canon law and state law}

\author{
Isidor, Metropolitan of Smolensk and Dorogobuzh (Tupikin R.V.) \\ Smolensk Orthodox Theological Seminary \\ 5 Timiryazeva St, Smolensk, 214000, Russia \\ E-mail: tupikinrv2017@mail.ru
}

\begin{abstract}
The author examines and explains the nature, features and ways of influence of canonical church law on state law, and also shows the reasons for scientific interest in these issues. According to the author, the influence of canon law (Lex Canonica) on state law is primarily manifested in the recognition by state judicial bodies of canon law norms and decisions of religious courts of religious organizations. Therefore, the article examines the extensive modern jurisprudence (USA and Canada), showing the recognition by the courts (state) of the autonomous exclusive competence of religious organizations in interpreting the norms of canon law. The author draws a conclusion about the difference between state law and church law (Lex Canonica) in nature, source basis, structure and ontology of their own, but at the same time, in the author's opinion, these two normative systems interact in a complex way, mutually affect each other.
\end{abstract}

Keywords: ecclesiastical law, canon law, theology, state law, intersections in law. 
For citation: Isidor (Tupikin R.V.), Metropolitan of Smolensk and Dorogobuzh. 2020. On the question of the modalities of joining and differentiating canon law and state law. NOMOTHETIKA: Philosophy. Sociology. Law series. 45 (4): 781-791 (in Russian). DOI 10.18413/2712-746X-2020-45-4-781-791

\section{Введение}

Вопросы соотношений, референций, взаимодействий государственного права и права церковного канонического, тем более в части влияния последнего на право государственное, - столь же сложны и мало проработаны, сколь и актуальны.

Церковь (в аспекте - как организация людей) живёт и функционирует не в безвоздушном пространстве, нередко нуждаясь в том, чтобы прибегать к праву государственному и даже к судебной государственной системе, к правоохранительным органам государства. Впрочем, здесь всё ясно - уголовные преступления явно не относятся к юрисдикции религиозной организации. Но много более неоднозначна и сложно онтологична ситуация с корреляцией канонического права и гражданского права.

Этим вопросам посвящён настоящий наш материал.

\section{Научный интерес к соотношению канонического права и права государственного}

Как пишет Сами Мехмети, «повторное открытие дайджестов Юстиниана и появление классического канонического права в XI веке знаменуют собой начало европейской правовой традиции. Римское право и каноническое право вместе образовали ius commune. В структуре и содержании коммуны ius римское право частично отвечало за юридическую технику и сложность, тогда как каноническое право отвечало за общие принципы. Из обильной казуистики Corpus iuris civilis средневековые юристы извлекли огромную массу юридических понятий, концепций и институтов. Моральный и теологический авторитет канонического права сделал его менее формальным и техническим по сравнению с римским правом. Каноническое право ставило потребности справедливости как свою важнейшую особенность. Многочисленные принципы частного права, которые даже сегодня составляют основу систем континентального права, во многих случаях изначально были разработаны на основе канонического права. Сравнивая римское право с каноническим правом, средневековые юристы признали недостатки формалистического и часто чрезмерно технического римского права. Каноническое право предложило действенные решения этой проблемы. Это привело в конечном итоге к включению общих принципов канонического права в римское право и потере части технической части римского права. Этот процесс завершили естествоиспытатели XVII-XVIII веков» [Mehmeti S., 2016, с. 164].

Научный интерес к соотношению канонического права и права государственного находил отражение в работах практически всех российских наиболее авторитетных специалистов по церковному каноническому праву (а равно по вопросам регулирования государственно-конфессиональных отношений) - как прошлых времён [Гавріил, архим., 1844; Горчаковъ, 1909; Суворовъ, 1889; Павловъ, 1902; Бердников, 1888], так и времени настоящего [Kuttner, 1950; Цыпин B., 1996; Messner etc., 2003; Dufaux etc. 2005].

Согласно А.С. Павлову, «на православном востоке право, церковное по происхождению, и по содержанию своих норм всегда было церковным. Если же и там церковь входила иногда, как определяющий авторитет, в область светского, мирского права, то она никогда не придавала принципиального значения своей законодательной деятельности в этой области; с другой стороны, православная церковь никогда принципиально не отрицала права светской христианской власти - принимать участие в образовании не только внешнего, но и внутреннего церковного права - под условием, конечно, чтобы светский законодатель действовал здесь так же, как действовала бы и сама церковь, т.е. в полном 
согласии с коренными началами церковного права и на основании или, по крайней мере, в духе положительных канонов древней Вселенской церкви» [Павлов, 1902, с. 8].

Каноническое право - это, согласно А. Лащуку, «наиболее ключевые нормы (правила) и административные постановления, которыми руководствуется христианское сообщество. Это слово происходит не только из христианской традиции, но и от греческого

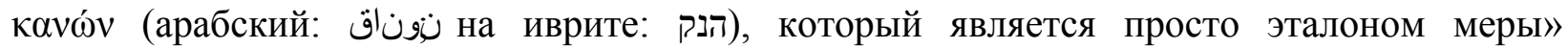
[Laschuk A., 2018, c. 4].

Принято выделять общее в каноническом праве разных церквей, даже и у Православных Церквей и Рисской католической церкви, и партикулярное. И эти части во взаимодействии с правом государственным онтологически различны, ведут себя по-разному. Но они все равно взаимодействуют.

Каноническое право, именуемое А.С. Павловым законами церковного порядка, «как внешняя оболочка церковной жизни должно соответствовать внутреннему существу и жизненному назначению самой церкви»; и «церковному праву, так же как и всякому другому, присущ характер принудительности, в том смысле, что оно возвышается над частною волею, действует на нее с силою необходимости. Конечно, церковь сама по себе не может принуждать физически, так, как принуждает к исполнению своих законов государство. Тем не менее и она имеет своего рода нудящую и карательную власть, которою и действует против своих отдельных членов, нарушающих общий порядок церковной жизни. В этом нельзя сомневаться, если взять во внимание, что в исключительном распоряжении церкви находятся известные права и блага, которые, поэтому, она же может и отнять, например права духовного сана, право каждого члена церкви на совершение для него известных церковных актов и т.п. Существование таких принудительных законов в церкви нисколько не противоречить христианскому учению о свободе воли: ибо кто признает себя членом церкви, тот тем самым изъявляет волю и принимает на себя обязанность повиноваться её законам и соблюдать существующий в ней порядок. Нет и быть не может никакого принуждения ко вступлению в церковь, но кто уже принадлежит к ней, тот необходимо подчиняется её законам, так как они основаны на положительной божественной воле и поставлены условиями, при соблюдении которых только и возможно для отдельных лиц достижение цели, открывающейся для них в церковном союзе. Таким образом, принудительная сила церковно-юридических норм происходит не из простой необходимости церковного порядка, а из положения отдельных лиц в этом порядке... Очевидно, что в церковном праве, в отличие от мирского, моменты внешнего принуждения и внутренней личной свободы вполне совпадают... Вопрос о положении церкви в сфере мирского права. Здесь церковь вполне и всецело зависит от государства, которое может признавать, может и не признавать её в качестве публичной корпорации. Итак, чтобы правильно судить об отношении церковного права к государственному, нужно постоянно имеет в виду различие внутреннего и внешнего права церкви. Признавая полную самостоятельность первого, мы нисколько не ограничиваем естественных и необходимых прав государства относительно церкви, не ставим её выше государства или в международных отношениях к нему» [Павлов, 1902, с. 9-12].

\section{Соотношение канонического права и гражданского права}

Согласно Джону Мерфи, церковь признает необходимость использования гражданского права в определённых вопросах ${ }^{1}$.

${ }^{1}$ Цит. по: Решение Верховного суда («Высшего суда справедливости») провинции Онтарио Канады от 31.08.2010 по делу «Харт против Римско-католической епископальной корпорации Кингстонской епархии» [Hart v. Roman Catholic Episcopal Corporation of the Diocese of Kingston, in Canada, 2010 ONSC 4709, Court file № CV-08-0068-00 / Ontario Superior Court of Justice, 
Как отмечает Александр Лащук, каноническое право часто использует гражданские нормы: в католическом Кодексе канонического права 1983 года [Кодекс канонического права, 2007] такое встречается двадцать один раз. Каноническое право иногда подчиняется гражданским нормам. Канон может включать гражданские нормы в каноническую сферу. Это также может происходить без явной ссылки на гражданские нормы, а просто со ссылкой на необходимость консультироваться с гражданским законодательством в области. Например, канон 105 Кодекса канонического права указывает, что правовая эмансипация несовершеннолетних должна соответствовать нормам гражданского права. Канон 877 указывает, что запись приемных родителей должна соответствовать нормам гражданского права. Канон 1540 присваивает доказательную силу документам в каноническом судебном разбирательстве в соответствии с тем, что определено в гражданском праве юрисдикции. В других канонах положения гражданского права не упоминаются в законе, а просто предписывается партиям следовать гражданскому праву. Например, каноны о приеме на работу мирян относятся к необходимости соблюдать гражданское право в юрисдикции. Пасторам также запрещается вступать в брак с теми, чей брак не может быть признан гражданским законодательством. Церковь также следует гражданскому (международному) праву в отношении своих дипломатических отношений. Хотя существует древняя практика, когда римский понтифик отправлял своих легатов в местные церкви, на современном языке апостольские нунции признаются не только как церковные представители определенной церкви, но так же как гражданские послы политического образования. Каноническое право указывает, что эти назначения должны соответствовать нормам международного права в отношении назначения и отзыва таких послов. Более того, каноническая система закрепляет определенные решения за гражданской властью. Канон 1692, например, позволяет епископу разрешить паре обратиться в гражданский суд, чтобы объявить о разводе. Это конкретное поручение действия, имеющего канонические последствия, то есть прекращения права на совместное проживание в браке, судебного решения гражданского судьи, признания его или ее полномочий и решения по делу, обычно поручаемому судебным решением в храм. Гражданское право, наоборот, может включать в себя и каноническое право. В некоторых странах это является результатом прямого закрепления соответствующих положений в конкордате. Например, во многих юрисдикциях, не относящихся к общему праву, церковные декларации о недействительности брака или церковное разлучение супругов будут иметь соответствующие гражданские последствия. Однако каноническое право может иметь гражданские последствия более косвенным образом [Laschuk, 2018].

Согласно Дугласу Стэмпу, «кодекс канонического права Римско-католической церкви («Канонический закон») является старейшей непрерывно действующей правовой системой в западном мире, предшествующей общему и гражданскому праву. Он обеспечивает внутренний церковный закон, который управляет церковью и ее членами. Когда люди поступают в семинарию, чтобы стать членами духовенства, они проходят несколько лет обучения. Обучение включает в себя изучение канонического права. Кроме того, перед рукоположением в дьяконов и священников кандидаты подают прошения и заявления под присягой, в которых они заявляют, что желают по своей доброй воле быть рукоположенными и соблюдать и руководствоваться наставлениями своих церковных начальников и принципами каноны» ${ }^{1}$.

31.VIII.2010] // <https://www.canlii.org/en/on/onsc/doc/2010/2010onsc4709/2010onsc4709.html>. (Абзац 21).

${ }^{1}$ Цит. по: Решение Верховного суда («Высшего суда справедливости») провинции Онтарио Канады от 31.08.2010 по делу «Харт против Римско-католической епископальной корпорации Кингстонской епархии» [Hart v. Roman Catholic Episcopal Corporation of the Diocese of Kingston, in Canada, 2010 ONSC 4709, Court file № CV-08-0068-00 / Ontario Superior Court of Justice, 


\section{Признание судами автономной исключительной компетенции за религиозными организациями в истолковании норм канонического права}

Влияние канонического права на право государственное прежде всего проявляется в признании государственными судебными органами норм канонического права и решений религиозных судов религиозных организаций.

Всё это вполне укладывается в концепт конструктивной светскости государства [Понкин, 2004, 2006, 2019] (во всяком случае, не в вульгарно-атеистическом истолковании светскости государства). И такая судебная практика представляет высокий интерес для наших исследовательских целей, поскольку государство устами своих судей прямо и открыто заявляет о наличии сложных корреляций канонического права и права государственного.

«Никакая краткая ёмкость правовых норм не может обеспечить надлежащего разъяснения всех мельчайших подробностей в содержании юридического понятия, - указывает Е.В. Аристов. - Тем более что многие из таких понятий являются многозначными, их значения варьируются в зависимости от контекста, коннотации, дискурса. Где взять нужные интерпретации с достаточно высокой степенью верифицированности? В научных исследованиях? Несомненно. Но в абсолютном большинстве случаев мы столкнёмся с тем, что разные авторы обосновывают совершенно полярные точки зрения на предмет, интерпретируют содержание того или иного права (или свободы), того или иного правового механизма или правового института совершенно противоречивым (по отношению друг к другу) образом. И здесь именно судебная практика служит тем огромным ресурсом производства юридико-лексических интерпретаций, их эмпирической проверки и закрепления в преемстве своих правовых позиций» [Аристов, 2015, с. 3-4].

Итак, приступим.

Согласно Решению Апелляционного суда штата Нью-Йорк (США) от 05.01.1874 по делу «Коннит против Реформатской протестантской голландской церкви» ${ }^{1}$, «во всех спорных случаях, когда нет явного отсутствия церковной юрисдикции, решения церковных судебных органов относительно их собственной юрисдикции в церковных вопросах должны иметь больший вес... Придя к выводу, что это был церковный вопрос и что церковные судебные органы имели в отношении него необходимую юрисдикцию, мы не можем спрашивать, действовали ли они в соответствии с законами и обычаями своей церкви, а также правильно ли они решили этот вопрос. Согласно устоявшемуся закону этой страны, неоднократно провозглашенному наиболее образованными судьями и высшими судами, в таких случаях гражданские суды должны принимать решения церковных судов как окончательные и обязательные для сторон».

Решение Верховного суда штата Пенсильвания (США) от 29.06.1846 по делу «Немецкая реформатская церковь против Содружества Зайбер»² гласило: «Решения церковных судов, как и любого другого судебного трибунала, окончательны; поскольку они более компетентные судьи в том, что составляет... церковную дисциплину... Все, кроме этих судов, должны признаваться некомпетентными судьями по вопросам веры,

31.VIII.2010] // <https://www.canlii.org/en/on/onsc/doc/2010/2010onsc4709/2010onsc4709.html>. (Абзацы 22 и 23$)$.

${ }^{1}$ Решение Апелляционного суда штата Нью-Йорк (США) от 05.I.1874 по делу «Коннит против Реформатской протестантской голландской церкви» [«George W. Connitt et al. v. The Reformed Protestant Dutch Church, of New Prospect et al.»] / New York Supreme Court, June $1871 / /$ $<$ https://www.courtlistener.com/opinion/3603850/connitt-v-rpdc-of-n-prospect/>.

${ }^{2}$ Решение Верховного суда штата Пенсильвания (США) от 29.06.1846 по делу «Немецкая реформатская церковь против Содружества Зайбер» [«German Reformed Church v. Commonwealth ex rel. Seibert». 3 Pa. 282 (1846). June 29, 1846 / Supreme Court of Pennsylvania] // $<$ https://cite.case.law/pa/3/282/>. 
церковной дисциплины и доктрины; а гражданские суды, если они окажутся настолько неразумными, чтобы попытаться контролировать свои решения по вопросам, входящим в их юрисдикцию, только погрузят себя в море неуверенности и сомнений, что приведет к чему угодно, кроме улучшения религии или нравственности».

Нам могут возразить, что это всё - дела давно минувших дней, выраженно архаично. Но дело в том, что есть и референтные судебные решения относительно совсем недавние.

Согласно Решению Верховного суда провинции Онтарио Канады от 31.08.2010 по делу «Харт против Римско-католической епископальной корпорации Кингстонской епархии» ${ }^{1}$ (дело касалось отстранения пастора от занимаемой должности и соответствующего прекращения его полномочий): «Должность священнослужителя может быть создана только посредством канонического права. Каноническое право также предусматривает срок полномочий и оговаривает обязанности и ответственность, связанные с исполнением этой должности в течение срока, на который она занимает. Наконец, Канонический Закон определяет обстоятельства, при которых священническое служение может быть прекращено... Должность священнослужителя была создана и регулируется каноническим правом. Каноническое право диктует обстоятельства, при которых священническое служение может быть прекращено. По этим причинам я прихожу к выводу, что отстранение отца Харта от должности пастора не подлежит рассмотрению нашими судами... Принимая во внимание существенный религиозный характер отношений между отцом Хартом и ответчиком, наши суды будут вмешиваться в религиозные споры только в двух случаях: 1) когда требования естественной справедливости не были удовлетворены внутренними процессами; или 2) когда эти внутренние процессы были исчерпаны... Отец Харт не предпринял никаких попыток найти какое-либо средство правовой защиты в соответствии с каноническим правом. Он не смог реализовать свои права, хотя его постоянно информировали о процессах... Суть иска между отцом Хартом и Архиепископией носит церковный характер, и этот суд не обладает юрисдикцией в отношении этого спора. Более того, внутренние процессы, предназначенные для разрешения этого спора, не нарушают принципов естественной справедливости, и отец Харт не исчерпал доступные ему внутренние процессы. По этим причинам данное разбирательство представляет собой процессуальное злоупотребление и приостанавливается» $(\S \S 25,31,38,44,45)$.

Решение Апелляционного суда провинции Онтарио Канады от 22.11.2011 по делу «Харт против Римско-католической епископальной корпорации Кингстонской епархии» ${ }^{2}$ гласило: «По общему правилу, Верховный суд обладает юрисдикцией рассматривать иски о неправомерном увольнении и нарушении трудового договора. Но из общего правила есть исключения. Одним из общепризнанных исключений является случай, когда существенный характер спора между работодателем и работником возникает из-за толкования, применения, администрирования или нарушения коллективного договора. Эти споры должны разрешаться в арбитражном порядке, а не в суде. Второе исключение - правила самоуправляющейся организации, особенно религиозной, предусматривают внутренний процесс разрешения споров. Лицо, добровольно решившее стать членом самоуправ-

${ }^{1}$ Решение Верховного суда («Высшего суда справедливости») провинции Онтарио Канады от 31.08.2010 по делу «Харт против Римско-католической епископальной корпорации Кингстонской епархии» [Hart v. Roman Catholic Episcopal Corporation of the Diocese of Kingston, in Canada, 2010 ONSC 4709, Court file № CV-08-0068-00 / Ontario Superior Court of Justice, 31.VIII.2010] // $<$ https://www.canlii.org/en/on/onsc/doc/2010/2010onsc4709/2010onsc4709.html>.

${ }^{2}$ Решение Апелляционного суда провинции Онтарио Канады от 22.11.2011 по делу «Харт против Римско-католической епископальной корпорации Кингстонской епархии» [Hart v. Roman Catholic Episcopal Corporation of the Diocese of Kingston, in Canada, 2011 ONCA 728 (CanLII) / Court of appeal for Ontario] $/ /<\mathrm{http}: / /$ canlii.ca/t/fnxj0 $>$. 
ляющейся организации и пострадавшее из-за решения этой организации, должно добиваться возмещения в рамках внутренних процедур организации. Суды будут вмешиваться во внутренние дела самоуправляющейся [в данном случае - церковной] организации только в двух ситуациях: когда внутренние процессы организации несправедливы или не соответствуют требованиям естественной справедливости; или если потерпевшая сторона исчерпала внутренние процессы организации. В последнем случае, с учётом любых разрешающих законодательных положений, апелляционный суд не будет рассматривать по существу внутреннее решение, а только определит, было ли решение приведено в исполнение в соответствии с правилами организации и требованиями естественного правосудия... Римско-католическая церковь - это самоуправляемая организация. Его каноническое право предусматривает внутренний процесс рассмотрения церковных споров... В тех случаях, когда административное постановление может повлиять на права стороны, каноническое право требует, чтобы сторона была уведомлена, имела возможность ответить и чтобы был беспристрастным суд. Каноническое право также предусматривает широкий спектр средств правовой защиты, включая замену другого постановления, денежную компенсацию и даже судебное разбирательство... Процесс внутреннего контроля в соответствии с каноническим правом соответствует требованиям естественного правосудия... По своей сути спор отца Харта с архиепископией носит церковный характер и подчиняется каноническому праву. Когда его назначили пастором, его назначение строго соответствовало каноническому праву... Должность пастыря является церковной. Каноническое право создает должность, определяет обязанности и ответственность по должности и описывает обстоятельства, при которых исполнение полномочий по должности может быть прекращено. Согласно каноническому праву, церковь может передать дело в гражданское право, но никогда не разрешала в судах дела об отстранении пастора от должности... По своей сути этот спор является церковным. Возмещение должно требоваться через внутренний процесс рассмотрения, установленный каноническим правом для споров церковного характера» (§§ 17-21, 23, 24).

В своём Решении Верховного суда провинции Онтарио Канады от 27.07.1999 по делу «Левиттс Кошер Фудс против Левина» судья Бенотто заявил (дело касалось иудаистской религии, но референтно рассматриваемому нами кругу вопросов и не раз упоминалось в судебных решениях по другим делам, связанным с католической церковью): «Понятно, что суды не хотят вмешиваться во внутренние дела религиозных организаций. Это лишило бы религиозную организацию права самостоятельно толковать свою доктрину. Наши суды неизменно утверждали, что гражданские суды не компетентны для решения вопросов религиозной доктрины. Верховный суд Канады постановил, что суды очень осмотрительно должны осуществлять юрисдикцию в отношении религиозных групп. При разрешении церковных споров суд не будет обращать внимание на существо решения, а скорее смотрит на соблюдение правил, процедурную справедливость и отсутствие недобросовестности и естественной справедливости... Суды определяют, связан ли вопрос с религиозной доктриной до такой степени, что суды должны вообще отказаться от участия... Суды будут проверять решения, принятые церковными органами, чтобы определить, соответствует ли решение законам и авторитету самой религиозной организации... [Лицо], действующее в религиозной среде, ... подчиняется религиозным законам, которые регулируют эту среду... В религиозном контексте делового мира, в котором истец решил работать и извлекать прибыль... следует следить за соблюдением правил этой системы».

\footnotetext{
${ }^{1}$ Решение Верховного суда провинции Онтарио Канады от 27.07.1999 по делу «Левиттс Кошер Фудс против Левина» [Levitts Kosher Foods Inc. v. Levin et al. 45 O.R. (3d) 147[1999] O.J. № 2785. Court File № 99-CV-163952-CM / Ontario Superior Court of Justice, July 27, 1999]// <https:/www.canlii.org/en/on/onsc/doc/1999/1999canlii14818 /1999canlii14818.html>.
} 
В Решении Верховного суда штата Нью-Джерси (США) от 23.01.1952 по делу «Бенджамин Кэбинет против Шапиро» ${ }^{1}$ (дело касалось иудаистской религии, но референтно рассматриваемому кругу вопросов и не раз упоминалось в делах, связанных с католической церковью ${ }^{2}$ ) говорилось, что истец, стремясь вести бизнес в отношении производства и оборота определённой религиозной еды, которая играет очень важную роль в религиозной вере членов таких общин, должен соответствовать канонам этой веры, касающимся этого предмета, если он желает продолжать этот бизнес с религиозной санкции. Он не может иметь или получать такую коммерческую выгоду, если он не соблюдает все требования правил, установленных этой религиозной организацией как предварительные условия для этого, и он также должен соблюдать решения религиозных судов, созданных и учрежденных для разрешения споров, касающихся этого предмета. Он не может претендовать на выгоду от бизнеса, не принимая на себя возложенное на него бремя. Решения религиозных судов по вопросам дисциплины, веры или церковных правил, обычаев или правил, влияющих на членов религиозной организации, должны признаваться государственными судами как окончательные и обязательные для них в их применении к рассматриваемому им делу, и государственные суды не будут расследовать или интересоваться прямо или косвенно противоречивыми утверждениями, касающимися практики или управления доктринальными делами религиозных групп, либо основаниями для наложения дисциплинарных мер за заявленные нарушения обязанностей религиозной группой, если только это не что-то из ряда вон выходящее (убийства, растление малолетних и т.д.).

В Решении Верховного суда провинции Онтарио Канады от 27.01.1994 по делу «Дерек Педерсен против Томаса Фултона и Римско-католической епископальной корпорации» ${ }^{3}$ было указано на необходимость рассмотрения спора об отстранении католического священника от должности и от отправления таинств в церковном суде в соответствии с положениями канонического права.

Решение Верховного суда штата Южная Каролина (США) от 09.12.1996 по делу «Пирсон против Церкви Бога» ${ }^{4}$ «Когда гражданское право зависит от церковного вопроса, решать его должен гражданский суд, а не церковный. Но гражданский суд рассматривает гражданское право, и не более того; ... Гражданские суды не будут рассматривать церковную доктрину или церковную дисциплину, а также не будут проверять регулярность судебных заседаний церковных судебных органов, занимающихся такими вопросами. Принятие такой юрисдикции было бы не только попыткой гражданских судов рассматри-

${ }^{1}$ Решение Верховного суда штата Нью-Джерси (США) от 23.01.1952 по делу «Бенджамин Кэбинет против Шапиро» [«Benjamin Cabinet, et ux., plaintiffs, v. rabbi Mosheh Shapiro, et als., defendants». 17 N.J. Super. 540 (1952) 86 A.2d 314 / Superior Court of New Jersey, Law Division. Decided January 23, 1952]// <https://www.canlii.org/en/on/onsc/doc/1999/1999canlii14818 /1999canlii14818.html>.

${ }^{2}$ См., например: Решение Верховного суда провинции Онтарио Канады от 27.07.1999 по делу «Левиттс Кошер Фудс против Левина» [Levitts Kosher Foods Inc. v. Levin et al. 45 O.R. (3d) 147[1999] O.J. № 2785. Court File № 99-CV-163952-CM / Ontario Superior Court of Justice, July 27, 1999]// <https://www.canlii.org/en/on/onsc/doc/1999/1999canlii14818 /1999canlii14818.html>.

${ }^{3}$ Решение Верховного суда провинции Онтарио Канады от 27.01.1994 по делу «Дерек Педерсен против Томаса Фултона и Римско-католической епископальной корпорации» [«Derek Pedersen v. Thomas Fulton and The Roman Catholic Episcopal Corporation». [1994] O.J. No. 168. DRS 94-11929. Action № 31469/93. January 27, 1994] / Ontario Court of Justice // $<$ https://www.theinquiry.ca/wordpress/documents/contact-me-2/pedersen-v-fulton/>.

${ }^{4}$ Решение Верховного суда штата Южная Каролина (США) от 09.12.1996 по делу «Пирсон против Церкви Бога» [«Pearson v. Church of God». 478 S.E.2d 849 (1996). № 24541. Decided December 9, 1996 / Supreme Court of South Carolina] // <https://law.justia.com/cases/south-carolina/supremecourt/1996/24541-2.html>. 
вать вопросы, в которых они не имеют специальных знаний, но и несовместимо с полной религиозной свободой, не ограничиваемой государственной властью... Ниже приведены общие принципы, которые вытекают из анализа вышеуказанных дел Верховного суда США и Южной Каролины: 1) суды не могут участвовать в разрешении споров в отношении религиозного права, принципов, доктрины, дисциплины, обычаев или администрации; 2) суды не могут избежать рассмотрения прав, вытекающих из гражданского права; 3) при разрешении таких гражданско-правовых споров суды должны принимать как окончательные и обязательные решения высших религиозных судебных органов в отношении религиозного права, принципа, доктрины, дисциплина, обычаи и администрация».

Решение Верховного суда США от 21.06.1976 по делу «Сербская православная епархия против Миливоевича» ${ }^{1}$ : «Всякий раз, когда вопросы дисциплины, веры, церковных правил, обычаев или закона решаются высшей церковной судебной властью, на которую был передан этот вопрос, судебные трибуналы должны принять такие решения как окончательные и обязательные... Действительно, суть религиозной веры заключается в том, что церковные решения принимаются и должны приниматься как вопросы веры, независимо от того, являются ли они рациональными или измеряемыми объективными критериями... Никакое исключение "произвола" - в смысле расследования, соответствуют ли решения высшего церковного суда иерархической церкви церковным законам и постановлениям - не согласуется с конституционным мандатом, согласно которому гражданские суды обязаны принимать решения высших судебных органов. религиозной организации с иерархической политикой в вопросах дисциплины, веры, внутренней организации или церковного правления, обычаев или закона. Чтобы гражданские суды проанализировали, являются ли церковные действия церковной судебной власти в этом смысле "произвольными", должны по своей сути повлечь за собой исследование процедур, которые канонический или церковный закон якобы требует от церковной судебной системы, или других основных критериев, по которым они выполняются. якобы решить церковный вопрос. Но это именно то расследование, которое запрещает Первая поправка; признание такого исключения подорвало бы общее правило, согласно которому религиозные споры не являются надлежащим предметом рассмотрения в гражданском суде, и что гражданский суд должен принимать церковные решения церковных трибуналов в том виде, в каком он их находит.

Выше приведенные экстракты из правовых позиций государственных судебных инстанций США и Канады (а надо сказать, аналоги мы встречаем в судебной практике Италии, Испании, Аргентины, Франции и мн. др. государств мира) уже показывают неоднозначность и сложную онтологичность столкновения норм канонического права и права государственного, но главное - отражают признание этого государством.

\section{Заключение}

Право государственное и право церковное каноническое (Lex Canonica), очевидно, совершенно различны по природе, источниковой основе, структуре и онтологии, но, вместе с тем эти две нормативные системы сложным образом взаимодействуют, взаимно влияют друг на друга. Признание контрагентов каждой из сторон различно, меняется во времени и в пространстве, но всегда имеет место.

${ }^{1}$ Решение Верховного суда США от 21.06.1976 по делу «Сербская православная епархия против Миливоевича» [Serbian Orthodox Diocese v. Milivojevich, 426 U.S. 696 (1976). Decided June 21, 1976 / U.S. Supreme Court] // <https://supreme.justia.com/cases/federal/us/426/696/>; <https: //caselaw.findlaw.com/us-supreme-court/426/696.html>. 


\section{Список источников}

1. Бердниковъ И.С. 1888. Краткій курсъ церковнаго права Православной Греко-россійской Церкви, съ указаніемъ главнъйшихъ особенностей католическаго и протестанскаго церковнаго права. Казань, Типографія Императорскаго Университета. ix; 294 с.

2. Гавріил, архим. 1844. Понятіе о церковномъ правђ и его исторія. Казань, Университетская типогр. 32 с.

3. Горчаковъ М.И. 1909. Церковное право: Краткій курсъ лекцій. С.-Петербугъ. 349 с. св. Фомы. 624 с.

4. Кодекс канонического права. 2007. М., Институт философии, теологии и истории

5. Павловъ А.С. 1902. Курсъ церковнаго права. Сергіевъ Посадъ, Типогр. Св.-Троицкой Сергіевой Лавры. Г. Фалькъ.

6. Суворовъ Н.С. 1889. Курсъ церковнаго права. Т. 1. Ярославль, Типо-литографія

7. Цыпин В. 1996. Курс церковного права. Учеб. пособие. М., Круглый стол по религиоз. образованию в Рус. православ. Церкви, Изд-во МФТИ, 442 с.

\section{Список литературы}

1. Аристов Е.В. 2015. Интерпретации содержания принципа социальности государства в правовых позициях судебных инстанций. М., Юнити-Дана: Закон и право. 199 с.

2. Понкин И.В. 2019. Спор с вульгарно-атеистическим радикалом о светскости государства (ответ на статью О.В. Мартышина): Концепт и онтология светского государства и светскости государства, многообразие моделей, дефектность идеологизированных подходов. М., Буки Веди, 42 с.

3. Понкин И.В. 2004. Светскость государства. М., Изд-во Учебно-научного центра довузовского образования. $466 \mathrm{c.}$

4. Понкин И.В. 2006. Современное светское государство: конструктивная светскость. М., Институт государственно-конфессиональных отношений и права. 390 с.

5. Dufaux J. etc. 2005. Liberté religieuse et régimes des cultes en Droit français. Textes, pratique administrative, jurisprudence. Nouvelle édition. Ed. par J. Dufaux, P. Dupuy, J.P. Durand, C. Dutheil de la Rochère, F. Gasztowtt, M. Guillaume, A.-V. Hardel, B. Jeuffroy. Paris, Les Éditions du Cerf. xviii; $1853 \mathrm{p}$.

6. Kuttner S. 1950. Natural law and canon law. Natural Law Institute Proceedings. 3: 83-116.

7. Laschuk A. 2018. Law in the Catholic Tradition and the Question of Church and State. Ottawa, Cardus religious freedom institute. $21 \mathrm{p}$.

8. Mehmeti S. 2016. The influence of Canon Law on Ius Commune in its formative period. SEEU Review. Issue 2. 11: 155-166.

9. Messner F. etc. 2003 Traité de Droit français des religions. Sous la direction de F. Messner, P.-H. Prélot, J.-M. Woehrling. Paris, Éditions du Juris-Classeur. xvii; 1317 p.

\section{References}

1. Aristov E.V. 2015. Interpretacii soderzhaniya principa social'nosti gosudarstva v pravovyh poziciyah sudebnyh instancij [Interpretation of the content of the principle of sociality of the state in the legal positions of courts]. M., Publ.: YUniti-Dana: Zakon i pravo. 199 p.

2. Ponkin I.V. 2019. Spor s vul'garno-ateisticheskim radikalom o svetskosti gosudarstva (otvet na stat'yu O.V. Martyshina): Kontsept i ontologiya svetskogo gosudarstva i svetskosti gosudarstva, mnogoobrazie modelei, defektnost' ideologizirovannykh podkhodov. [Dispute with a vulgar-atheistic radical about the secularism of the state (response to the article by O. V. Martyshin): the Concept and ontology of the secular state and the secularism of the state, the variety of models, the defect of ideologized approaches]. M., Publ.: Buki Vedi. 42 p.

3. Ponkin I.V. 2004. Svetskost' gosudarstva [Secularism of the state]. M., Publ.: Uchebnonauchnogo centra dovuzovskogo obrazovaniya. $466 \mathrm{p}$.

4. Ponkin I.V. 2006. Sovremennoe svetskoe gosudarstvo: Konstruktivnaya svetskost'. [Modern secular state: Constructive secularism]. M., Publ.: Institut gosudarstvenno-konfessional'nyh otnoshenij i prava. 390 s. (In Russian) 
5. Dufaux J. etc. 2005. Liberté religieuse et régimes des cultes en Droit français. Textes, pratique administrative, jurisprudence. Nouvelle édition. Ed. par J. Dufaux, P. Dupuy, J.P. Durand, C. Dutheil de la Rochère, F. Gasztowtt, M. Guillaume, A.-V. Hardel, B. Jeuffroy. Paris, Les Éditions du Cerf. xviii; $1853 \mathrm{p}$.

6. Kuttner S. 1950. Natural law and canon law. Natural Law Institute Proceedings. 3: 83-116.

7. Laschuk A. 2018. Law in the Catholic Tradition and the Question of Church and State. Ottawa, Cardus religious freedom institute. $21 \mathrm{p}$.

8. Mehmeti S. 2016. The influence of Canon Law on Ius Commune in its formative period. SEEU Review. Issue 2. 11: 155-166.

9. Messner F. etc. 2003 Traité de Droit français des religions. Sous la direction de F. Messner, P.-H. Prélot, J.-M. Woehrling. Paris, Éditions du Juris-Classeur. xvii; 1317 p.

\section{ИНФОРМАЦИЯ ОБ АВТОРЕ}

Исидор (Тупикин Р.В.), митрополит Смоленский и Дорогобужский, кандидат юридических наук, ректор Смоленской Православной Духовной Семинарии Смоленской Епархии Русской Православной Церкви, доцент кафедры богословских и церковноисторических дисциплин семинарии, г. Смоленск, Россия

\section{INFORMATION ABOUT THE AUTHOR}

Isidore (R.V. Tupikin), Metropolitan of Smolensk and dorogobuzhsky, candidate of law, rector of the Smolensk Orthodox Theological Seminary of the Smolensk Diocese of the Russian Orthodox Church, associate Professor of the Department of theological and Church-historical disciplines of the Seminary, Smolensk, Russia 